\title{
UJI AKTIVITAS ANTIOKSIDAN FRAKSI ETIL ASETAT DAUN MIANA (Coleus atropurpureus Benth)
}

\author{
Dwi Nur Afifah ${ }^{1, *}$, Aditya Fridayanti ${ }^{1}$, Muhammad Amir Masruhim² \\ ${ }^{1}$ Laboratorium Penelitian dan Pengembangan Kefarmasian "Farmaka Tropis", \\ Fakultas Farmasi, Universitas Mulawarman, Samarinda \\ ${ }^{2}$ Program Studi Pendidikan Kimia, Fakultas Keguruan dan Ilmu Pendidikan, \\ Universitas Mulawarman, Samarinda \\ *Email : dwidna78@yahoo.com
}

\begin{abstract}
Miana leaf (Coleus atropurpureus Benth) is one of the plants traditionally used as a medicine to cure some diseases, such as cough, food stimulant, and neutralizing toxins (antitoksik). This research aims to find out antioxidant activity of ethyl acetate fraction miana leaf. Miana leaf (Coleus atropurpureus Benth) were extracted with ethanol using maceration method then fractionated using $n$-hexane and ethyl acetate. Antioxidant activity test using scavenging 2,2-diphenyl-1pikrilhidrazy (DPPH) radical method, where the absorbance is measured on $\lambda$ maks $516.4 \mathrm{~nm}$ by spectrophotometer UV-Vis. The result of research shows the ethyl acetate fraction miana leaves have antioxidant activity by DPPH radicals with $I C_{50}$ value of $33.768 \mathrm{ppm}$.
\end{abstract}

Keywords: Antioxidant, DPPH, Coleus atropurpureus Benth, Ethanol, ethyl acetate fraction.

\begin{abstract}
ABSTRAK
Daun Miana (Coleus atropurpureus Benth) merupakan salah satu tanaman tradisional yang digunakan sebagai obat untuk menyembuhkan beberapa penyakit, seperti batuk, perangsang nafsu makan, dan penetralisir racun (antitoksik). Penelitian ini bertujuan untuk mengetahui aktivitas antioksidan fraksi etil asetat daun miana. Daun miana (Coleus atropurpureus Benth) diekstraksi dengan pelarut etanol menggunakan metode maserasi kemudian difraksinasi secara bertahap menggunakan pelarut n-heksana dan etil asetat. Uji aktivitas antioksidan menggunakan metode radikal 2,2-difenil-1-pikrilhidrazi (DPPH), dimana absorbansi yang diukur pada $\lambda$ maks $516,4 \mathrm{~nm}$ dengan menggunakan alat spektrofotometer UV-Vis. Hasil penelitian menunjukkan bahwa fraksi etil asetat
\end{abstract}


daun miana memiliki aktivitas antioksidan terhadap radikal DPPH dengan nilai $\mathrm{IC}_{50}$ $33,768 \mathrm{ppm}$

Kata Kunci : Antioksidan, DPPH, Coleus atropurpureus Benth, Etanol, Fraksi etil asetat

\section{PENDAHULUAN}

Antioksidan secara normal terdapat di dalam tubuh, sehingga tubuh dapat mengatasi efek radikal bebas, tetapi jika jumlah radikal bebas terlalu banyak, maka antioksidan endogen yang terdapat dalam tubuh tidak mencukupi sehingga radikal dapat mengakibatkan kerusakan sel. Untuk itu diperlukan jumlah antioksidan yang lebih banyak, salah satunya adalah antioksidan yang berasal dari luar tubuh (eksogen) [1].

Berdasarkan sumber perolehannya terdapat dua macam antioksidan yaitu antioksidan alami dan antioksidan sintetik. Antioksidan alami mampu melindungi tubuh terhadap kerusakan yang disebabkan spesies oksigen reaktif, mampu menghambat terjadinya penyakit degeneratif serta mampu menghambat peroksidae lipid pada makanan. Penggunaan antioksidan alami mengalami peningkatan karena selain mencegah berkembangnya radikal bebas di dalam tubuh juga dapat memperbaiki sel-sel tubuh yang rusak [2].

Daun miana berkhasiat sebagai pereda batuk, perangsang nafsu makan, dan penetralisir racun (antitoksik). Kandungan kimia yang terdapat pada daun mina antara lain alkaloid, flavonoid, dan saponin [3]. Kandungan senyawa tersebut dapat berperan aktif sebagai antioksidan alami.

Salah satu uji untuk menentukan aktivitas antioksidan penangkap radikal adalah metode DPPH (1,1-Diphenyl-2-picrylhidrazyl). Metode DPPH memberikan informasi reaktivitas senyawa yang diuji dengan suatu radikal stabil. DPPH memberikan serapan kuat pada panjang gelombang $517 \mathrm{~nm}$ dengan warna violet gelap. Penangkap radikal bebas menyebabkan elektron menjadi berpasangan yang kemudian menyebabkan penghilangan warna yang sebanding dengan jumlah elektron yang diambil [4].

Tujuan penelitian ini adalah untuk mengetahui aktivitas antioksidan dari fraksi etil asetat daun miana (Coleus atropuroureus Benth) terhadap radikal DPPH dan potensi aktivitas antioksidan yang dinyatakan dalam nilai $\mathrm{IC}_{50}$.

\section{METODE PENELITIAN}

\section{Bahan}

Bahan sampel yang digunakan dalam penelitian ini adalah daun miana yang diambil dari kebun yang berada di Gang Immanuel Jalan Mangkupalas, Samarinda Seberang Kalimantan Timur. Bahan penyari dan fraksinasi adalah etanol 96 \%, nheksana, etil asetat, dan air suling. Bahan kimia lainnya adalah DPPH. 


\section{Peralatan}

Peralatan yang digunakan dalam penelitian ini antara lain timbangan analitik (Precisa XB 220 A), corong pisah $\left(\right.$ Pyrex $\left.^{\circledR}\right)$, gelas kimia $\left(\right.$ Pyrex $\left.^{\circledR}\right)$, rotary evaporator, Spektrofotometer UV-Vis, labu ukur 10ml; 50ml (Pyrex $\left.{ }^{\circledR}\right)$, vortex, waterbath, dan mikropipet 100-1000 $\mu \mathrm{L}$

\section{PROSEDUR PENELITIAN}

\section{Persiapan Bahan}

Daun miana dipanen dan dicuci dengan air untuk menghilangkan kotoran dan cemaran, dikeringkan dengan cara diangin-anginkan. Sampel yang telah kering ditimbang dan disimpan dalam wadah tertutup.

\section{Pembuatan Ekstrak}

Ekstrak daun miana dibuat dengan cara maserasi. Sebanyak 200 gram simplisia daun miana dimasukkan ke dalam wadah gelas tertutup, kemudian direndam dengan larutan etanol $96 \%$ sebanyak 3 Liter dan dibiarkan selama 5 hari sambil sesekali diaduk. Setalah 5 hari, sampel yang direndam tersebut disaring menggunakan kertas saring menghasilkan filtrat dan ampas. Hasil filtrat dievaporasi menggunakan rotary evapolator, diperoleh ekstrak kental daun miana. Sedangkan ampas diremaserasi kembali dengan etanol $96 \%$.

\section{Pembuatan Fraksi}

Ekstrak kental yang dihasilkan tersebut diuapkan seluruh pelarut etanol dengan menggunakan waterbath. Ekstrak ditimbang 5 gram lalu dilarutkan dalam air sebanyak $100 \mathrm{~mL}$. Kemudian difraksinasi dengan n-heksana $100 \mathrm{~mL}$ dalam corong pisah, setalah bening larutan n-heksana diganti dengan etil asetat $100 \mathrm{~mL}$. Ditampung fraksi etil asetat daun miana lalu diuapkan dan dihasilkan fraksi kental daun miana.

\section{Pengukuran Aktivitas Antioksidan Dengan Metode Peredaman DPPH}

\section{Penentuan panjang gelombang maksimum}

Sebanyak 2 mg DPPH dilarutkan dalam etano1 $96 \%$ dan dimasukkan dalam labu takar gelap $50 \mathrm{~mL}$ hingga tanda batas $(40 \mathrm{ppm})$. Lakukan scanning maks dengan alat spektrofotometer pada kisaran 500-600 nm. Gunakan etanol sebagai blanko.

\section{Analisis Aktivitas Antioksidan fraksi etil asetat daun miana}

Fraksi etil asetat daun miana dibuat dalam larutan stok 100 ppm di dalam labu takar $50 \mathrm{~mL}$ dengan etanol $96 \%$, kemudian dibuat seri konsentrasi 10, 20, 30, 40, 50, 60, dan $70 \mathrm{ppm}$ di dalam labu takar $10 \mathrm{~mL}$. Diambil $2 \mathrm{~mL}$ tiap seri konsentarasi, selanjutmya ditambahkan $2 \mathrm{~mL}$ pereaksi DPPH dalam tabung reaksi tertutup dan didiamkan selama 30 menit. Larutan dihomogenisasi dengan vortex 
selama 30 detik dan dibaca serapan aktivitasnya pada spektrofotometer UV-Vis pada panjang gelombang maksimum. Blanko yang digunakan larutan DPPH dalam etanol tanpa penambahan larutan uji. Besarnya aktivitas antioksidan dihitung dengan rumus [4].

Persen aktivitas antioksidan $=\frac{\text { Absorbansi blankol-Absorbansi sampel }}{\text { Absorbansi blanko }} \times 100 \%$

\section{HASIL DAN PEMBAHASAN}

\section{Ekstraksi dan Fraksinasi}

Proses maserasi sangat menguntungkan dalam mengekstrak senyawa bahan alam karena, dengan perendaman, pelarut akan mempunyai waktu interaksi dengan sampel lebih lama untuk melakukan pemecahan dinding dan membran sel sampel. Hal ini terjadi karena adanya perbedaan tekanan antara didalam dan diluar sel sehingga senyawa metabolit sekunder yang ada didalam sitoplasma akan keluar dan terlarut dalam pelarut organik [5].

Hasil maserasi berupa filtrat berwarna coklat kemerahan sebanyak 2,5 Liter. Kemudian diuapkan menggunakan rotary evaporator hingga diperoleh ekstrak kental yang berwarna coklat kehitaman. Hasil ekstrak etanol dapat dilihat pada tabel 1 .

Tabel 1. Hasil ekstrak etanol daun miana

\begin{tabular}{cccc}
\hline \multirow{2}{*}{$\begin{array}{c}\text { Berat Sampel } \\
(\mathrm{g})\end{array}$} & \multicolumn{2}{c}{ Berat Wadah } & \multirow{2}{*}{ Ekstrak kental $(\mathrm{g})$} \\
\cline { 2 - 3 } & Cawan Kosong $(\mathrm{g})$ & Cawan + Ekstrak $(\mathrm{g})$ & \\
\hline 200 & 280 & 288,4 & 8,4 \\
\hline
\end{tabular}

Ekstrak kering etanol daun miana ditimbang sebanyak 5 g kemudian dilarutkan dalam air suling $100 \mathrm{~mL}$ selanjutnya difraksinasi dengan $\mathrm{n}$-heksana 100 $\mathrm{mL}$ sebanyak 10 kali. Lapisan $\mathrm{n}$-heksana yang diperoleh dimasukkan cawan dan diuapkan di atas waterbath sampai kental sehingga diperoleh fraksi n-heksana sebanyak 2,3 g. lapisan air difraksinasi kembali dengan etil asetat $100 \mathrm{~mL}$ hingga bening kemudian hasil fraksi etil asetat diuapkan di atas waterbath diperoleh fraksi etil asetat sebanyak 1,4 g. Hasil rendemen dapat dilihat pada tabel 2.

Tabel 2. Hasil rendemen fraksi n-heksana dan etil asetat daun miana

\begin{tabular}{cccccc}
\hline \multirow{2}{*}{$\begin{array}{c}\text { Berat } \\
\text { Ekstrak } \\
\text { etanol }(\mathrm{g})\end{array}$} & Fraksi (g) & Kosong $(\mathrm{g})$ & Fraksi $(\mathrm{g})$ & $\begin{array}{c}\text { Fraksi } \\
\text { kental }(\mathrm{g})\end{array}$ & $\begin{array}{c}\text { Rendemen } \\
(\%)\end{array}$ \\
\hline \multirow{2}{*}{5,00} & n-heksana & 190,6 & 192,9 & 2,3 & 1,15 \\
& etil asetat & 190,4 & 191,8 & 1,4 & 0,7 \\
\hline
\end{tabular}




\section{Hasil pengujian aktivitas antioksidan fraksi etil asetat daun miana}

Penentuan panjang gelombang maksimal dilakukan dengan melarutkan DPPH dengan etanol $96 \%$ dalam konsentrasi $40 \mathrm{ppm}$. Kemudian dikur absorbansinya dengan menggunakan range panjang gelombang 500-600 nm. Range tersebut ditentukan dari warna komplementer atau warna yang diamati dari larutan DPPH yaitu warna violet gelap sedangkan warna yang diserap oleh spektrofotometer UV-Vis adalah warna hijau [6]. Lalu didapatkan absorbansi tertinggi pada panjang gelombang 516,4 $\mathrm{nm}$.

Pengujian absorbansi peredaman radikal bebas DPPH dilakukan terhadap fraksi etil asetat dibuat dengan berbagai konsentrasi kemudian diukur serapan absorbansi pada panjang gelombang 516, $4 \mathrm{~nm}$ dengan waktu reaksi 30 menit. Pengujian ini dilakukan replikasi sebanyak tiga kali. Absorbansi yang diperoleh dihitung aktivitas persen peredaman. Hasil dapat dilihat pada tabel 3.

Tabel 3. Hasil aktivitas antioksidan pengujian fraksi etil asetat daun miana

\begin{tabular}{ccccccc}
\hline \multirow{2}{*}{ No. } & Konsentrasi & \multicolumn{4}{c}{ Absorbansi } & \multirow{2}{*}{$\begin{array}{c}\text { Aktivitas }(\% \\
\text { peredaman) }\end{array}$} \\
\cline { 3 - 5 } & $(\mathrm{ppm})$ & 1 & 2 & 3 & Rata-rata & 3,594 \\
1 & 10 & 0,704 & 0,842 & 0,787 & 0,778 & 39,033 \\
3 & 20 & 0,481 & 0,495 & 0,501 & 0,492 & 43,866 \\
4 & 30 & 0,462 & 0,450 & 0,446 & 0,453 & 70,136 \\
5 & 40 & 0,222 & 0,229 & 0,271 & 0,241 & 79,554 \\
6 & 50 & 0,176 & 0,175 & 0,144 & 0,165 & 82,899 \\
7 & 60 & 0,135 & 0,124 & 0,155 & 0,138 & 91,202 \\
\hline
\end{tabular}

Aktivitas antioksidan penangkapan radikal yaitu DPPH oleh fraksi etil asetat daun miana ditunjukkan pada gambar 1 .

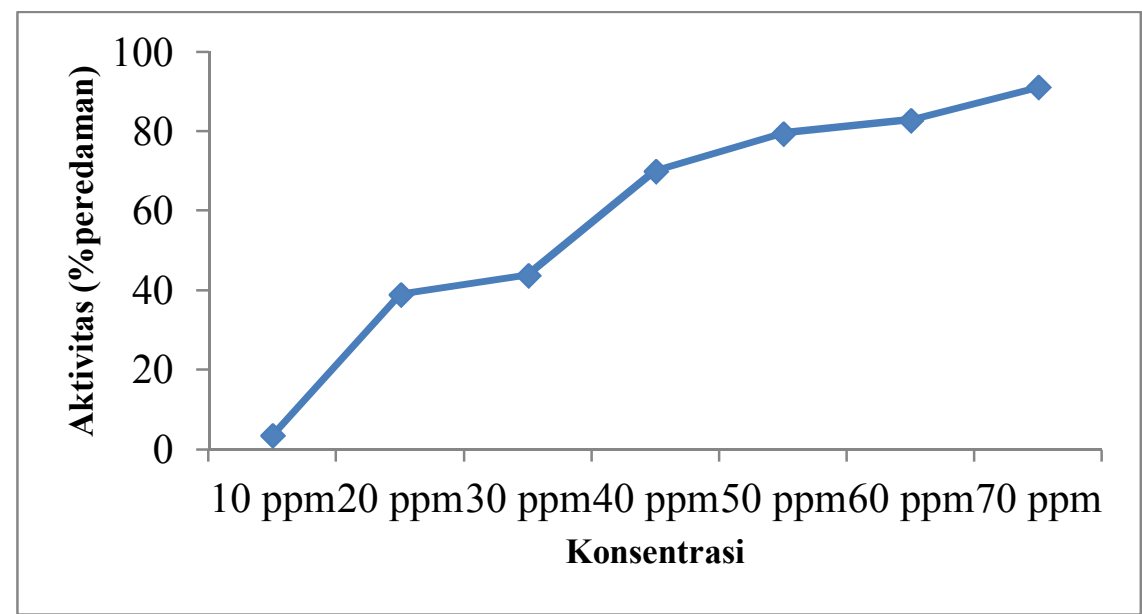

Gambar 1. Aktivitas Antioksidan Penangkap Radikal DPPH Fraksi Etil Asetat Daun Miana 


\section{Penentuan $\mathrm{IC}_{50}$}

Perhitungan harga dari $\mathrm{IC}_{50}$ dilakukan dengan cara menginterpolasikan persen peredaman (50 \%) ke dalam kurva hubungan konsentrasi larutan uji dengan persen peredaman [7]. Dari data antara konsentrasi fraksi etil asetat daun miana dengan persen peredaman diperoleh persamaan garis regresi

$\mathrm{Y}=1,379 \mathrm{x}+3,434$, dimana $\mathrm{r}$ hitung $=0,954$

Berdasarkan data tersebut, dapat disimpulkan adanya hubungan linier antara konsentrasi dengan persen peredaman pada fraksi etil asetat daun miana, sehingga diperoleh $\mathrm{IC}_{50} 33,768 \mathrm{ppm}$. Nilai $\mathrm{IC}_{50}$ yaitu konsentrasi yang diperlukan antioksidan untuk menangkap 50\% radikal DPPH [4].

Metode DPPH merupakan metode yang mudah, cepat dan murah untuk menetapkan aktivitas antioksidan. Senyawa 2,2-diphenyl-1-picrylhydrazil (DPPH) adalah sebuah molekul yang mengandung senyawa radikal bebas yang stabil. Keberadaan sebuah antioksidan yang dapat menyumbangkan elektron kepada DPPH, menghasilkan warna kuning yang merupakan ciri spesifik dari reaksi radikal DPPH. Hasil perubahan warna dari ungu menjadi kuning sebanding dengan jumlah elekton yang ditangkap. Perubahan yang terjadi pada reaksi radikal DPPH tersebut dapat diukur dengan spektrofotometri sinar tampak [8].

Aktivitas peredaman radikal bebas DPPH fraksi etil asetat daun miana ditentukan oleh berbagai senyawa antioksidan yang terdapat di dalam daun miana. Untuk mengetahui senyawa aktif yang memberikan aktivitas antioksidan perlu dilakukan penelitian lanjutan berupa skrining dan isolasi senyawa aktif yang dipandu oleh uji aktivitas (activity test guided isolation).

\section{KESIMPULAN}

Berdasarkan penelitian yang telah dilakukan, maka dapat disimpulkan bahwa fraksi etil asetat daun miana memiliki aktivitas antioksidan terhadap radikal DPPH dengan nilai $\mathrm{IC}_{50} 33,768$ ppm.

\section{DAFTAR PUSTAKA}

[1] Sibue, P. 2003. Antioksidan Senyawa Ajaib Penangkal Penuaan Dini. Sinar Harapan. Yogyakarta.

[2] Sunarni, T. 2005. Aktivitas Antioksidan Penangkap Radikal Bebas Beberapa Kecambah Dari Biji Tanaman Familia Papilionaceae. Jurnal Farmasi Indonesia Volume 2, Nomor 2, hal 53-61.

[3] Harmanto, Ning. 2007. Herbal untuk Keluarga: Jus Herbal Segar dan Menyehatkan. Elex Media Komputindo. Jakarta.

[4] Kuncahyo, Ilham dan Sunardi. 2007. Uji Aktivitas Antioksidan Ekstrak Belimbing Wuluh (Averrhoa bilimbi, L.) Terhadap 1,1-diphenyl-2picrylhydrazil (DPPH). Seminar Nasional Teknologi 2007 (SNT 2007). 
[5] Anonim. 2000. Parameter Standar Umum Ekstrak Tanaman Obat. Ditjen POM, Departemen Kesehatan RI. Jakarta.Gandjar, Ibnu Gholib, dan Abdul Rohman. 2011. Kimia Farmasi Analisis. Pustaka Pelajar. Yogyakarta.

[6] Gandjar, Ibnu Gholib, dan Abdul Rohman. 2011. Kimia Farmasi Analisis. Pustaka Pelajar. Yogyakarta.

[7] Umayah, Evi dan Moch. Amrun H. 2007. Uji Aktivitas Antioksidan Ekstrak Buah Naga (Hylocereus undatus (Haw.) Britt. \& Rose). Jurnal Ilmu Dasar, Volume 8, Nomor 1, hal 89.

[8] Marliana, Eva. 2012. Aktivitas Antioksidan Ekstrak Etanol Daun Andong (Cordyline fruticosa L. A. Cheval). Mulawarman Scientifie, Volume 11, Nomor 1, hal 76-77. 